\title{
Early Direct Antiglobulin Test Negativity after Bendamustine and Rituximab Treatment in Chronic Lymphocytic Leukemia: Two Cases
}

\author{
Bendamustin ve Rituksimab Tedavisi ile Erken Direkt Antiglobülin Testi Negatifliği Elde \\ Edilen Iki Kronik Lenfositik Lösemi Olgusu
}

(D) Rafet Eren, (D) Elif Suyanı

University of Health Sciences, Istanbul Training and Research Hospital, Clinic of Hematology, Istanbul, Turkey

To the Editor,

Autoimmune hemolytic anemia (AlHA) can emerge at any stage of chronic lymphocytic leukemia (CLL); furthermore, patients can present with AlHA before diagnosis [1]. Although direct antiglobulin test (DAT) positivity is one of the hallmarks of AlHA, it was also demonstrated to be associated with advanced disease [2] and poor prognosis [3] independent of hemolytic anemia in CLL patients [3]. Here we present two CLL patients with AlHA whose DAT results became negative shortly after receiving bendamustine-rituximab (BR) chemotherapy.

\section{Case 1}

A 69-year-old male patient who was being followed without treatment for CLL in Rai stage 2 for 6 months presented with abdominal pain and jaundice. Laboratory tests were as follows: leukocytes: $55,140 / \mu \mathrm{L}$, lymphocytes: $51,240 / \mu \mathrm{L}$, hemoglobin: $5.3 \mathrm{~g} / \mathrm{dL}$, platelets: $46,000 / \mu \mathrm{L}$, indirect bilirubin: $2.89 \mathrm{mg} / \mathrm{dL}$, haptoglobin: $2 \mathrm{mg} / \mathrm{dL}$, lactate dehydrogenase (LDH): $1585 \mathrm{U} / \mathrm{L}$, and DAT positive for Immunoglobulin G (IgG) (no titer provided). Imaging studies showed compressing conglomerate lymph node masses in the abdomen. The patient was started on steroid and BR treatments. The hemoglobin value rose to normal levels and DAT became negative after 3 cycles of BR. The patient received 6 cycles of BR chemotherapy and steroids were interrupted at the $5^{\text {th }}$ month of treatment. The patient has been followed in remission for 1 year.

\section{Case 2}

A 75-year-old female patient who was being followed without treatment with the diagnosis of CLL in Rai 0 stage for 8 years was admitted due to weakness and fatigue. Laboratory tests were as follows: leukocytes: $78,840 / \mu \mathrm{L}$, lymphocytes: $67,020 / \mu \mathrm{L}$, hemoglobin: $6.3 \mathrm{~g} / \mathrm{dL}$, platelets: $255,000 / \mu \mathrm{L}$, indirect bilirubin: $2.58 \mathrm{mg} / \mathrm{dL}$, LDH: $504 \mathrm{U} / \mathrm{L}$, haptoglobin: $1 \mathrm{mg} / \mathrm{dL}$, corrected reticulocyte count: $5.2 \%$, and DAT positive for $\lg G(4+)$. The patient was started on steroid treatment and subsequently BR therapy was added due to increased lymphocyte doubling time. After the first cycle, the DAT titer dropped to 3+. Hemoglobin value rose to normal levels and DAT became negative after 3 cycles of BR. Steroids were ceased at the $7^{\text {th }}$ month of treatment; The patient completed 6 cycles of BR and has been followed in remission for 1 year.

While the standard approach in CLL patients with AlHA issteroids, systemic chemotherapy is recommended in refractory cases and in patients requiring treatment for CLL [1]. Although first-line therapy in CLL patients is the fludarabine-cyclophosphamiderituximab regimen, the wide use of BR chemotherapy, especially in advanced-age patients, has brought up the application of this combination in patients with AIHA $[4,5]$. In a recent study including $26 \mathrm{CLL}$ patients who had AlHA and received BR, the response rate was $81 \%$ for AIHA and $77 \%$ for CLL [4]. Similarly, our patients also responded well in terms of CLL and AIHA. The most striking point was that DAT became negative in a short period of time (after 3 cycles of BR).

In conclusion, in addition to being a plausible option in advanced-age CLL patients, BR seems to be an important treatment of choice in terms of eliminating the poor prognostic factor of DAT positivity and assuring safe cessation of steroid treatment due to rapid achievement of DAT negativity.

Keywords: Chronic lymphocytic leukemia, Autoimmune hemolytic anemia, Bendamustine, Rituximab

Anahtar Sözcükler: Kronik lenfositik lösemi, Otoimmün hemolitik anemi, Bendamustin, Ritüksimab

Informed Consent: Informed consent was obtained from both patients.

Conflict of Interest: The authors of this paper have no conflicts of interest, including specific financial interests, relationships, and/or affiliations relevant to the subject matter or materials included.

\section{References}

1. Zent CS, Kay NE. Autoimmune complications in chronic lymphocytic leukaemia (CLL). Best Pract Res Clin Haematol 2010;23:47-59. 
2. Abbas SA, Zeeshan R, Sultan $S$, Irfan SM. Direct Coombs test positivity in B-chronic lymphoid leukemia: a marker of advanced clinical disease. Asian Pac J Cancer Prev 2015;16:6007-6010.

3. Quinquenel A, Al Nawakil C, Baran-Marszak F, Eclache V, Letestu R, Khalloufi M, Boubaya M, Le Roy C, Varin-Blank N, Delmer A, Levy V, AjchenbaumCymbalista F. Old DAT and new data: positive direct antiglobulin test identifies a subgroup with poor outcome among chronic lymphocytic leukemia stage A patients. Am J Hematol 2015;90:5-8.
4. Quinquenel A, Willekens $C$, Dupuis J, Royer B, Ysebaert L, De Guibert $S$, Michallet AS, Feugier P, Guieze R, Levy V, Delmer A. Bendamustine and rituximab combination in the management of chronic lymphocytic leukemia-associated autoimmune hemolytic anemia: a multicentric retrospective study of the French CLL intergroup (GCFLLC/MW and GOELAMS). Am J Hematol 2015;90:204-207.

5. Hallek M. Chronic lymphocytic leukemia: 2017 update on diagnosis, risk stratification, and treatment. Am J Hematol 2017;92:946-965.

\title{
Demodicidosis Accompanying Acute Cutaneous Graft-Versus-Host Disease after Allogeneic Stem Cell Transplantation
}

\author{
Allojeneik Kök Hücre Nakli Sonrası Akut Graft Versus Host Hastalığına Eşlik Eden \\ Demodisidoz
}

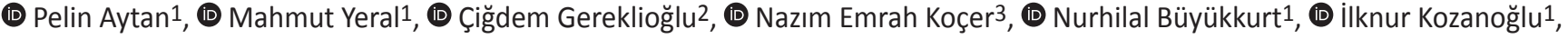 \\ (1) Hakan Özdoğu1, (1) Can Boğa1 \\ ${ }^{1}$ Başkent University Faculty of Medicine, Adana Dr. Turgut Noyan Application and Research Center, Clinic of Hematology, Adana, Turkey \\ ${ }^{2}$ Başkent University Faculty of Medicine, Department of Family Medicine, Adana, Turkey \\ ${ }^{3}$ Başkent University Faculty of Medicine, Adana Dr. Turgut Noyan Application and Research Center, Clinic of Pathology, Adana, Turkey
}

To the Editor,

A 39-year-old female with acute myeloid leukemia was admitted to our transplantation clinic with face eruption without any pruritus. The eruption had occurred 28 days after she underwent an allogeneic hematopoietic stem cell transplantation (SCT). She was allografted with $6.12 \times 10^{6}$ nonmanipulated CD34+ cells from a fully matched sibling donor after a conditioning regimen including busulfan $(12.8 \mathrm{mg} /$ $\left.\mathrm{m}^{2}\right)$, fludarabine $\left(150 \mathrm{mg} / \mathrm{m}^{2}\right)$, anti-thymocyte globulin (30 $\mathrm{mg} / \mathrm{kg}$ ), and total body irradiation (400 Gy/day). Graft-versushost disease (GVHD) prophylaxis comprised methotrexate at $12 \mathrm{mg} /$ day for 3 days and cyclosporine $\mathrm{A}$ at $75 \mathrm{mg}$ twice daily. No recent changes had been made to the medication. Neutrophil and thrombocyte engraftment both occurred on day 11 . The toxicity related to the regimen was mild, being assigned the first grade for oral mucosa according to the Bearman scale [1]. The findings of the physical examination were patchy and confluent erythema of the face, suspicious for cutaneous acute GVHD. There were no other skin changes except that of the palms and soles. Neither intestinal nor hepatic acute GVHD occurred. Laboratory evaluation revealed a white blood cell count of $12,000 / \mu \mathrm{L}$, a hemoglobin level of $11.5 \mathrm{~g} / \mathrm{dL}$, a platelet count of $158,000 / \mu \mathrm{L}$, and an absolute neutrophil count of $8400 / \mu \mathrm{L}$. A 4-mm skin punch biopsy was performed [2]. There were lymphocytes and polymorphic neutrophils that attacked hair follicles and two Civatte bodies. Histochemically Demodex folliculorum was diagnosed with PAS staining within the hair follicles (Figures $1 \mathrm{~A}$ and 1B). Even with lymphocytes attacking hair follicles and Civatte bodies suggesting GVHD, Demodex folliculitis can mimic acute GVHD (Figures $1 \mathrm{C}$ and 1D). Demodicidosis was treated successfully with local 1\% metronidazole and 5\% permethrin. Methylprednisolone was also administered from the beginning of the symptoms and the dosing was reduced by $8 \mathrm{mg}$ every week. The skin eruptions on the face and the neck resolved on day +52 .

Demodex folliculitis after allogeneic SCT is seen rarely and, as far as we know, our case is the sixth reported case $[3,4,5,6]$. The most important differential diagnosis of Demodex folliculitis within the first 100 days after allogeneic SCT is acute GVHD. The infestation by Demodex sp. can be associated with immune suppression. The differential diagnosis of facial erythema after bone marrow transplantation includes acute GVHD, drug eruptions, systemic lupus erythematosus, viral exanthema, toxic erythema of chemotherapy, drug-induced photosensitivity, and photodermatitis [3]. In our case there 